\title{
Lack of Expression of the Epstein-Barr Virus (EBV) Gene Products, EBERs, EBNA1, LMP1, and LMP2A, in Breast Cancer Cells
}

\author{
C.G. Deshpande, S. Badve, N. Kidwai, and R. Longnecker \\ Department of Pathology (CGD, SB, NK) and Department of Microbiology/lmmunology (CGD, RL), Northwestern \\ University, Chicago, Illinois
}

\begin{abstract}
SUMMARY: Epstein-Barr virus (EBV), a gamma herpesvirus, has been associated with a variety of human malignancies such as Burkitt's lymphoma, Hodgkin's lymphoma, NPC, and gastric cancer. A controversy regarding the association of EBV with breast cancers has recently been reported in the literature. These reports have mainly used the DNA detection techniques of polymerase chain reaction and Southern blot hybridization, with the inherent lacunae associated with these techniques for signal localization. Our group has studied EBV association with breast cancer by using in situ hybridization for detecting nonpolyadenylated EBV RNA (EBERs), along with using protein localization technique of immunohistochemistry, studying the EBV nuclear antigen 1 (EBNA1) and the latent membrane proteins (LMP1 and LMP2A). This is the first article analyzing the expression of LMP2A in breast cancer cells. In all of our 43 female breast cancer cases under study, we failed to detect expression of any of the EBV viral gene products tested. (Lab Invest 2002, 82:1193-1199).
\end{abstract}

$F$ pstein-Barr virus (EBV), also designated human $C$ herpesvirus 4 is a gamma herpesvirus of the lymphocryptovirus subfamily (for review, Longnecker, 1998). Humans are the exclusive natural host for EBV, and it is usually carried lifelong as an asymptomatic infection (Henle and Henle, 1979). Ubiquity and persistence, characteristics of herpes virus infections, are two notable features of EBV infection (for review, Rickinson and Kieff, 1996). EBV was the first human tumor virus identified by its strong association with endemic Burkitt's lymphoma, a noncleaved cell nonHodgkin's lymphoma (Epstein et al, 1964). Subsequently, EBV has been linked to the development of other lymphoid and non-lymphoid malignancies such as Hodgkin's disease, certain T-cell lymphomas, AIDS associated lymphomas or post-transplantation lymphoproliferative disorders, as well as epithelial tumors such as undifferentiated nasopharyngeal carcinomas (NPC) and a proportion of gastric cancers (Baumforth et al, 1999; Crawford et al, 1981; Hamilton-Dutoit et al, 1991; Herbst et al, 1991; Imai et al, 1994; Niedobitek et al, 1991; Old et al, 1966; Pallesen et al, 1991; Purtilo et al, 1978; Shibata et al, 1991; zur Hausen et al, 1970).

\section{DOI: 10.1097/01.LAB.0000029150.90532.24}

Received April 15, 2002

$R L$ is a Stohlman Scholar of the Leukemia and Lymphoma Society of America. RL is supported by Public Health Service grants CA62234 and CA73507 from the National Cancer Institute and DE13127 from the National Institute of Dental and Craniofacial Research.

Address reprint requests to: Dr. Richard Longnecker, Department of Microbiology/Immunology, Northwestern University, 303 E Chicago Avenue, Ward 6-231, Chicago, IL 60611.E-mail: r-longnecker@northwestern.edu
Lytic phase and latency are the two essential characteristics in the progression of EBV infection towards malignant transformation. Various viral proteins are expressed in these two phases, which are interrelated. Transition from latent infection to lytic replication can occur spontaneously or can be induced in B-cell cultures. Depending on the location and differentiation state of the infected B cell, four different programs of gene expression are observed in EBV infected B cells in vivo. The three programs that do not result in virion production have been designated growth, default, and latency based on the differences in the expression patterns of latent viral genes (for review, Thorley-Lawson, 2001). The growth program expresses all nine known latent proteins: the six EBV nuclear antigens (EBNA1, EBNA2, EBNA3A, EBNA3B, EBNA3C, and EBNALP), three latent membrane proteins (LMP1, LMP2A, and LMP2B), and the nonpolyadenylated EBV RNAs (EBERs). In the default program, EBNA1, LMP1, LMP2A, and the EBERs are expressed, providing necessary signals that are thought to allow infected lymphoblasts to differentiate into memory $B$ cells. In the latency program, which has a much more restricted patterned of viral gene expression, very few viral genes are expressed. The transcript for LMP2A has been consistently detected, and recent reports suggest the EBERs are also expressed (for review, Thorley-Lawson, 2001). This low level of viral gene expression allows persistence of the virus in resting recirculating memory cells in a way that is nonpathogenic and not detectable by the immune system (for review, Thorley-Lawson, 2001). Production of infectious virus is the essential feature 
of fourth and final gene expression program found in humans latently infected with EBV.

The classical view of EBV latency, which is based on EBV related cancers, has three types (for review, Rickinson and Kieff, 1996). Latency I is observed in Burkitt's lymphoma and is identified by the expression of the EBERs (EBV encoded small nonpolyadenylated mRNAs 1 and 2) and EBNA1. Hodgkin's disease and NPCs are examples of latency type II, wherein latent membrane proteins LMP1, LMP2A, LMP2B, nuclear antigen EBNA-1, and EBERs are expressed. In latency type III, all six EBNAs and the three EBV LMPs are expressed along with the EBERs. Type III latency is observed in lymphocytoid cell lines and posttransplant lymphoproliferative disorders (for review, Rickinson and Kieff, 1996).

Breast cancer is an epidemiologically significant health problem all over the world with over 800,000 new cases diagnosed every year (Parkin et al, 1999). Breast cancer alone is expected to account for $203,500(31 \%)$ of all new cancer cases among women in 2002 in the United States with an estimated 39,600 female deaths due to breast cancer in 2002 (Jemal et al, 2002). Recent studies have suggested an etiological role for EBV in breast cancer. These studies remain controversial because other studies have questioned this association (Bonnet et al, 1999; Brink et al, 2000; Chu et al, 1998, 2001; Fina et al, 2001; Gaffey et al, 1993; Glaser et al, 1998; Horiuchi et al, 1994; Labrecque et al, 1995; Lespagnard et al, 1995; Magrath and Bhatia, 1999; McCall et al, 2001; Touitou et al, 2001; Yasui et al, 2001). These reports have mainly used the techniques of Southern blotting and PCR for the detection of the EBV genome. The detection of EBV DNA in a tumor by PCR usually does not distinguish between the presence of the virus in the tumor cell population and the presence of EBV in "bystander" B cells in the tissue. For a meaningful analysis of EBV infection, it is therefore necessary in many instances to establish the cellular localization of the virus or viral gene products using morphology-based techniques. In vitro studies by Nyormoi (1979) had shown the activation of EBV in human mammary carcinoma cell line MCF-7 on cocultivation with EBV positive lymphoblastoid cell lines. However, factors leading to activation could not be elucidated, as not all non-EBV cell lines gave similar results.

To investigate the potential role of EBV in breast cancer, we examined the expression of the EBERs, EBNA1, LMP1, and LMP2A in breast cancer tissues. Examining these four EBV gene products allowed us to identify each of the different types of EBV latency. EBERs 1 and 2 are small nonpolyadenylated RNAs that are not essential for the transformation of primary $B$ cells by EBV but are the most abundant EBV RNAs in latently infected cells and hence are useful as a marker for the detection of latent EBV infection (Ambinder and Mann, 1994). EBNA1 has been shown to be essential for the maintenance of the EBV genome in latent infections by linking the viral genome to the cellular chromosome, insuring the virus is replicated in dividing cells as though it were part of the cellular genome (Yates et al, 1985). LMP1 and LMP2A are both ligand-independent cell-surface signaling molecules. LMP1 mimics a constitutively active TNF family receptor, activating signaling pathways such as NF-kappa B (for review, Eliopoulos and Young, 2001). LMP2A mimics an activated B-cell receptor in B lymphocytes (for review, Merchant et al, 2001) but has also been shown to alter the growth characteristics of epithelial cells (Scholle et al, 1999, 2000). We were particularly interested in examining the expression of LMP2A in breast cancer tissues both because of this recent observation in epithelial cells and because it had not been examined in any of the previous studies examining EBV gene expression in breast cancer tissues.

\section{Results \\ Clinicopathologic Features}

Our study included cases of female breast cancer only. We had 33 cases in the greater than 50 years age group and 10 cases in the less than 50 years group. The size of these tumors varied from $0.8 \mathrm{~cm}$ in diameter to the largest being $8.5 \mathrm{~cm}$ in diameter. The majority (23/43) of the cases had a tumor diameter less than $2.0 \mathrm{~cm}$ while 4 cases had a tumor diameter of more than $5.0 \mathrm{~cm}$. Histologically, we had 36 cases of infiltrating ductal carcinoma, 2 cases of infiltrating lobular carcinoma, and 5 cases where the tumors had mixed ductal and lobular morphology. No case of medullary carcinoma was included in our series. Based on the Scarf-Bloom-Richardson grading system, we had 8 cases of grade I, 24 cases of grade II, and 11 cases of grade III tumor. An almost equal distribution of cases was noted in detection of lymph node involvement by tumor. Biologic marker profile of these tumors showed estrogen receptor positivity in 37 cases and progesterone receptor positivity in 21 cases. C-erb2 membrane staining was reported positive in only 8 of our cases while p53 status was positive in only 4 cases.

\section{In Situ Hybridization for EBERs}

Control tonsillar sections provided with the EBV probe in situ hybridization (ISH) kit (NCL-EBV-K; Novocastra Laboratories Ltd., Newcastle upon Tyne, United Kingdom) showed strong nuclear positivity (Fig. 1A). Our sections did not show positive staining, either in the tumor cells or adjacent breast lobules. Sections from one of our cases showed presence of lymphocytes staining positive for EBV-ISH probe. As shown in Figure $1 \mathrm{~B}$, one of the positively staining lymphocytes was close to breast tumor cells. Also, as shown in Figure 1C, two more positively stained lymphocytes were identified in another focus of the section where prominent lymphocytic infiltrate was also seen. Poly-dT staining confirmed the preservation of mRNA in these sections under study. 

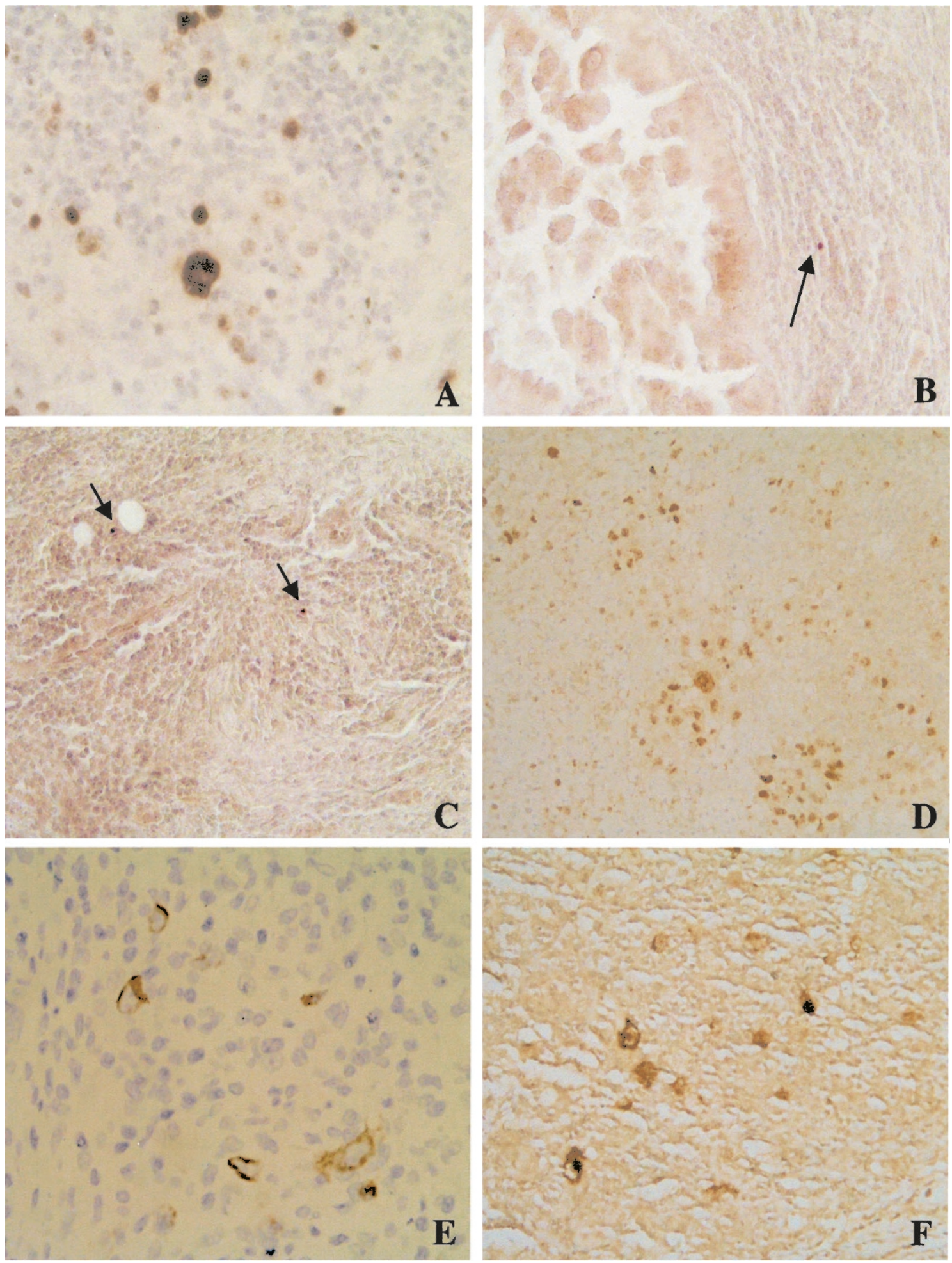

Figure 1.

Expression of Epstein-Barr virus (EBV) gene products. Nonpolyadenylated EBV RNA (EBERs) in situ hybridization positivity in control tonsil section (A). Section showing positively stained lymphocyte (small arrow), adjacent to breast cancer cells (B). Section showing positively stained lymphocytes (small arrows), amidst prominent lymphoid infiltrate in another focus from the same section as in Figure 1B (C). EBV nuclear antigen 1 (EBNA1) positive staining in control tonsil section (D). Latent membrane proteins (LMP)1 positive staining in control section of Hodgkin's disease (E). LMP2A positive staining in control section of Hodgkin's disease (F). In situ hybridization (A to C), immunoperoxidase (D to F); original magnification $\times 40(A, D), \times 20(B, C, E, F)$. 


\section{Immunohistochemistry}

EBNA-1. Nuclear staining was noted in the infected tonsillar tissue controls (Fig. 1D). Weaker granular nuclear staining was also noted in few of these tonsillar lymphocytes. However, none of our cases under study showed any presence of nuclear positivity, either in the tumor or adjacent breast lobules or in the lymphocytes.

LMP1 and LMP2A. Although strong cytoplasmic staining was noted in our control sections from a case of Hodgkin's disease (LMP1, Fig. 1E; LMP2A, Fig. 1F), none of our breast tumor sections showed any positivity, either in the tumor or adjacent breast lobules or in the lymphocytes.

\section{Discussion}

Breast cancer is a heterogeneous disease, accounting for nearly one of every three cancers diagnosed in American women. Among cancers in females, developing breast cancer has the highest probability (12.5\%) of occurring, with one in every eight women ultimately developing breast cancer (Jemal et al, 2002). Between 1987 and 1998, the incidence rates have increased by $0.5 \%$ per year (Parkin et al, 1999). Various risk factors such as, age, family history, early menarche, and late menopause are nonmodifiable, while factors such as alcohol consumption, use of postmenopausal hormones, or obesity after menopause are modifiable. Some factors, such as sex hormones, increase the risk by lifetime exposure (Harris et al, 1992; Henderson, 1993; Phillips et al, 1999). To identify different etiologic pathways, one has to examine the association of known and suspected risk factors. To determine association, one has to show statistically consistent cause and effect relationship. When the suspected agent is ubiquitous in the population such as EBV, the presence of which can be demonstrated in upwards of $90 \%$ to $95 \%$ of adult human population, it becomes all the more difficult to prove its association with the most common cancer in adult female population (ie, breast cancer), which also has a higher incidence in an older population $(>50$ years), suggesting an increased risk due to lifetime exposure.

Labrecque et al (1995) had demonstrated the presence of EBV genetic information in at least $20 \%$ of breast cancer cases assessed using the techniques of PCR amplification and in situ hybridization using probes corresponding to similar regions of the viral genome (BamHI-W, covering IR1 repetitive region, and BamHIC, encoding EBER 1 and 2 segments). The association of EBV with breast cancer was arrived at by deductive analysis of the results obtained from PCR and ISH experiments. Because, in their study, not all samples nor all cells in any particular sample scored positive for EBV, the authors suggested that EBV, when detected in breast tumors, may be an innocent passenger in tumor cells or may be present in a circulating B lymphocyte found within the tumor. Alternatively, EBV negative tumors may have lost the virus after the virus had played a role in the initial transformation process.

Bonnet et al (1999), using the techniques of PCR (BZLF1, LMP1, and EBER2), Southern blot analysis (BamHI-W), and immunohistochemical detection of EBNA1, showed the presence of EBV genome in tumors (51\%) and in healthy tissue (10\%), suggesting that EBV is mainly restricted to the tumor $(p<0.001)$. However, in situ hybridization on three EBV PCRpositive cases failed to confirm the PCR results. Immunohistochemistry for EBNA1 demonstrated selective positivity in only $5 \%$ to $30 \%$ of tumor cells of the PCR positive breast tumors in comparison with the majority of NPC tumor cells used as controls. In this study, out of the 51 PCR positive samples, only 10 were investigated by both Southern blot analysis and/or by immunohistochemistry ( $\mathrm{IHC})$, and positive results were observed by at least one of these and not both of them in all cases under study. Although this study has used different techniques such as Southern blot analysis, PCR, and immunohistochemistry to study the association, Brink et al (2000), using similar techniques, have been unable to obtain similar results. Furthermore, using RT-PCR for transcripts encoding EBNA1 and for rightward transcripts from the BamHI-A region of the EBV genome, negative results were noted. Also, the EBERs were not detected by in situ hybridization. Brink et al (2000) also noted EBNA1 positivity by 2B4 Mab IHC even in one PCR negative breast carcinoma sample, suggesting the nonspecific nature of the antibody used. Similarly, Hemminki and Dong (1999) and Altschuler (1999), based on epidemiologic model of standardized incidence ratios and the logic of historic antiquities, have made a case against the association and causătion of breast cancer by EBV.

Fina et al (2001) have performed by far the largest study of 509 primary invasive ductal breast cancers from areas with varying risks of NPC to determine the association of EBV with breast cancer, which they showed to be present in $31.8 \%$ of their samples and showed that the load of intratumoral EBV genome differs according to the geographical area and the risk associated with NPC. Using laser capture microdissection combined with real-time quantitative PCR, they showed intratumoral variation of EBV status in the malignant epithelial cells, varying from negative to markedly positive, leaving room for doubts regarding association. In fact, where GAPDH is low, EBV genome copy number is high in one of their two samples studied.

Glaser et al (1998) reported negative results in their study of 107 cases using EBER1 transcripts by in situ hybridization, which included one with subsequent NPC and one in which lymphocytes were EBERpositive. This study covered a diverse population from 21 hospitals in 7 counties from the San Francisco Bay Area of northern California to reflect the spectrum of age, sex, and ethnic groups associated with variation in breast cancer incidence in the United States. Lespagnard et al (1995), using PCR, EBER in situ hybridization, and IHC for LMP1, failed to find EBV in 
10 medullary carcinomas. Gaffey et al (1993) also had found no evidence of EBV association with 35 cases of medullary carcinoma by PCR amplification of DNA from these cases.

Chu et al (2001), in an attempt to resolve this controversy, used the techniques of IHC (for EBNA1, LMP1, and BZLF1), ISH for EBER1, PCR using primers detecting EBNA3B (EBNA4), and LMP1 and Southern blot analysis for EBV terminal repeat sequences. 10\% of cases showed EBER 1 positivity in less than $0.1 \%$ of tumor cell population. EBNA1 positivity was seen in less than $1 \%$ of total tumor cells in $12 / 48$ cases. LMP1 and BZLF1 staining was negative in all the cases studied. PCR studies for EBNA3C (EBNA4) and LMP1 were seen in $10 \%$ of cases. Southern blot analysis was similarly negative. Significantly, in this study, $71 \%$ of PCR positive cases showed prominent lymphocytic infiltration $(p<0.013)$. In this whole exercise, only one case showed positivity for both EBNA1 and EBER1, but in different cell populations. This is in contrast to other EBV associated malignancies, for which a higher percentage of cells is usually positive. This group has also expressed their reservations about the nonspecific nature of positivity by EBNA1 monoclonal antibody 2B4 and hence would not like to consider EBNA1 immunohistochemical positivity as evidence of EBV infection in the absence of other confirmatory studies.

Interestingly, Yasui et al (2001), in their population based epidemiological associations between infectious mononucleosis, young adulthood Hodgkin disease (YAHD), and breast cancer risk, have proposed a hypothesis that "delayed" primary EBV infection (ie, primary infection occurring during adolescence or adulthood) is associated with elevated breast cancer risk. This group has suggested an apparent paradoxical inverse correlation between molecular versus nonmolecular epidemiological evidence, stating that the factor responsible for the elevated risk of breast cancer and YAHD is not the EBV genome itself but an EBV induced host response and hence could possibly explain the absence of EBV genome in appreciable fractions of Hodgkin disease and breast cancer cases.

Our group decided to study the expression of EBV in breast cancer using in situ hybridization for detection of EBERs and three different antibodies against the latent viral antigens EBNA1 (2B4), LMP1 (CS1-4), and LMP2A (15F9). This approach would detect the different types of latencies of EBV associated malignancies at present known to us. Although the use of PCR to detect EBV has the benefits of ease and sensitivity, this exquisite sensitivity increases the likelihood of detecting EBV within nonmalignant cells (see Fig. 1, B and C). Also, DNA in situ hybridization methods using BamHI W repeats as a target have been criticized for lack of sensitivity and poor signal to noise ratio (Glaser et al, 1998; Labrecque et al, 1995). Considering the unavoidable possibility of breast tissue contamination by lymphocytes and the resultant amplification of DNA by using PCR techniques, we used the techniques of EBERs in situ hybridization and immunohistochemistry to study EBER transcription and viral protein expression.

We used established protocols and antibodies for the detection of EBERs, EBNA1, and LMP1, but, in addition, we studied the expression of another LMP, LMP2A, using the monoclonal antibody $15 \mathrm{~F} 9$ for the first time. Data supports a role for LMP2A in modifying the normal program of B-cell development to favor the maintenance of EBV latency and to prevent inappropriate activation of EBV lytic cycle (for review, Merchant et al, 2001). The consistent expression of LMP2A in Hodgkin's disease and NPCs, both examples of type II latency, suggests an important function for LMP2A in EBV oncogenesis. Scholle et al (2000) have shown that LMP2A in epithelial cells inhibits cell differentiation and activates the PI3-kinase-Akt pathway. Down regulation of cadherin expression was also noted in LMP2A expressing cells, suggesting a role in metastatic behavior.

None of our 43 cases of breast carcinoma were positive for EBERs, EBNA1, LMP1, and LMP2A in breast cancer cells in spite of good positive staining in our controls. The presence of positively stained lymphocytes close to breast cancer cells in one of our cases under study (Fig. 1, B and C) confirms the possibility of contamination by lymphocytes when techniques such as PCR and Southern blot hybridization are used.

Use of poly-dT as control also confirmed the preservation of RNA in our sections. The lack of detection of any of these EBV gene products suggests the absence of any type of EBV latency in breast cancer cells. Because the techniques we used allow for the identification and localization of the cell in which the signal is detected, contamination by lymphocytes or their DNA amplification can be excluded. As hypothesized by Hemminki and Dong (1999) as well as by Yasui et al (2001), if breast cancers are associated with EBV, probably due to host immune response factors, then surrogate markers for identification of cellular or cytokine related immune response would have to be used for identifying EBV association with breast cancer, which still may not answer the question of association without doubt.

\section{Materials and Methods}

\section{Breast Cancer Samples}

We selected 43 newly diagnosed cases of invasive carcinoma of the breast from our surgical pathology registry at Northwestern Memorial Hospital. These cases were selected for their histological grades according to the Scarf-Bloom-Richardson grading system so as to obtain a representation of all the three grades of ductal carcinoma (Elston and Ellis, 1991). Paraffin blocks were selected from the hematoxylin and eosin stained sections of formol-alcohol fixed tissues, which showed adequate amount of tumor on the section along with adjacent normal breast ductal tissue. Four micrometer sections were cut from these paraffin blocks, floated in molecular biology grade 
water, and dried on silane-coated slides. RNAse free precautions were carried out for section cutting as well as throughout the experiments for in situ hybridization.

\section{In Situ Hybridization}

In situ hybridization was performed on these sections using a fluorescein conjugated EBV probe for detection of EBER transcripts (EBV Probe ISH Kit; Novocastra Laboratories Ltd.). A fluorescein conjugated poly-dT probe was used to determine the RNA preservation. EBV infected tonsil sections supplied with the kit were used as positive controls. Fluorescein labeled random oligonucleotide cocktail probe supplied with the kit was used as a negative control probe. 5-Bromo-4-chloro-3-indolyl phosphate/Nitroblue tetrazolium (BCIP-NBT) alkaline phosphatase enzyme substrate was used for chromogenic detection. Strong nuclear positivity was observed for EBERs by in situ hybridization in control samples.

\section{Immunohistochemistry}

LMP1 was detected using the mouse monoclonal antibody CS1-4 in a dilution of 1:250 after antigen retrieval in 0.1 M Citra buffer (HK-086-9K; Biogeneux, San Ramon, California) for 15 minutes at high power in a microwave oven, then incubating for 2 hours at $37^{\circ} \mathrm{C}$ with the primary antibody, later using horseradish peroxidase labeled anti-mouse polymer, dilution 1:200, (P0447; DAKO Corp, Carpenteria, California), as the secondary antibody and 3,3' diaminobenzidine as substrate for chromogenic detection.

LMP2A was detected using the rat antibody $15 \mathrm{Fg}$ in a dilution of 1:20000. Antigen retrieval for 30 minutes at high power in a microwave oven using $0.1 \mathrm{M}$ Citra buffer (Biogeneux) was also performed. Sections were incubated with the primary antibody overnight at $4^{\circ} \mathrm{C}$. Horseradish peroxidase labeled anti-rat secondary antibody made in rabbit was used, dilution 1:100 (P0162, DAKO Corp). Tyramide signal amplification (PerkinElmer Life Science, Boston, Massachusetts) system was used for detection before using 3,3' diaminobenzidine as the chromogenic substrate.

EBNA1 was detected using the rat antibody 2B4 in a dilution of 1:500. Antigen retrieval for 60 minutes at high power in a microwave oven using $0.1 \mathrm{M}$ Citra buffer (Biogeneux) was also performed in this case. Sections were incubated with the primary antibody overnight at $4^{\circ} \mathrm{C}$. Anti-rat secondary antibody and tyramide signal amplification system with 3,3' diaminobenzidine as chromogenic substrate was used for detection.

Hodgkin's disease affected lymph node sections were used as positive controls for LMP1 and LMP2A, while EBV infected tonsil sections were used as positive controls for EBNA-1 detection. Cytoplasmic positivity was noted for the two LMPs, with strong to granular nuclear positivity was seen for EBNA-1. Respective isotypic sera and antibody diluent were used as negative controls.
Both EBNA1 antibody 2B4 and LMP2A antibody 15F9 were kindly provided by $\mathrm{Dr}$. Elisabeth Kremmer (Forschungszentrum fur Umwelt und Gesundheit $\mathrm{GmbH}$, Institut fur Immunologie, Munchen, Germany).

\section{References}

Altschuler EL (1999). Re: Detection of Epstein-Barr virus in invasive breast cancers. J Natl Cancer Inst 91:2126-2127.

Ambinder RF and Mann RB (1994). Epstein-Barr-encoded RNA in situ hybridization: Diagnostic applications. Hum Pathol 25:602-605.

Baumforth KR, Young LS, Flavell KJ, Constandinou C, and Murray PG (1999). The Epstein-Barr virus and its association with human cancers. Mol Pathol 52:307-322.

Bonnet M, Guinebretiere JM, Kremmer E, Grunewald V, Benhamou E, Contesso G, and Joab I (1999). Detection of Epstein-Barr virus in invasive breast cancers. J Natl Cancer Inst 91:1376-1381.

Brink AA, van Den Brule AJ, van Diest $P$, and Meijer CJ (2000). Re: Detection of Epstein-Barr virus in invasive breast cancers. J Natl Cancer Inst 92:655-656.

Chu JS, Chen CC, and Chang KJ (1998). In situ detection of Epstein-Barr virus in breast cancer. Cancer Lett 124:53-57. Chu PG, Chang KL, Chen YY, Chen WG, and Weiss LM (2001). No significant association of Epstein-Barr virus infection with invasive breast carcinoma. Am J Pathol 159:571578.

Crawford DH, Edwards JM, Sweny P, Hoffbrand AV, and Janossy G (1981). Studies on long-term T-cell-mediated immunity to Epstein-Barr virus in immunosuppressed renal allograft recipients. Int $\mathrm{J}$ Cancer 28:705-709.

Eliopoulos AG and Young LS (2001). LMP1 structure and signal transduction. Semin Cancer Biol 11:435-444.

Elston CW and Ellis IO (1991). Pathological prognostic factors in breast cancer. I. The value of histological grade in breast cancer: Experience from a large study with long-term follow-up. Histopathology 19:403-410.

Epstein MA, Achong BG, and Barr YM (1964). Virus particles in cultured lymphoblasts from Burkitt's lymphoma. Lancet 1:702-703.

Fina F, Romain S, Ouafik L, Palmari J, Ben Ayed F, Benharkat S, Bonnier P, Spyratos F, Foekens JA, Rose C, Buisson M, Gerard H, Reymond MO, Seigneurin JM, and Martin PM (2001). Frequency and genome load of Epstein-Barr virus in 509 breast cancers from different geographical areas. $\mathrm{Br} \mathrm{J}$ Cancer 84:783-790.

Gaffey MJ, Frierson HF Jr, Mills SE, Boyd JC, Zarbo RJ, Simpson JF, Gross LK, and Weiss LM (1993). Medullary carcinoma of the breast. Identification of lymphocyte subpopulations and their significance. Mod Pathol 6:721-728.

Glaser SL, Ambinder RF, DiGiuseppe JA, Horn-Ross PL, and Hsu JL (1998). Absence of Epstein-Barr virus EBER-1 transcripts in an epidemiologically diverse group of breast cancers. Int J Cancer 75:555-558.

Hamilton-Dutoit SJ, Pallesen G, Franzmann MB, Karkov J, Black F, Skinhoj P, and Pedersen C (1991). AIDS-related lymphoma. Histopathology, immunophenotype, and association with Epstein-Barr virus as demonstrated by in situ nucleic acid hybridization. Am J Pathol 138:149-163. 
Harris JR, Lippman ME, Veronesi U, and Willett W (1992). Breast cancer (1). N Engl J Med 327:319-328.

Hemminki K and Dong C (1999). Re: Detection of EpsteinBarr virus in invasive breast cancers. J Natl Cancer Inst 91:2126; discussion 2127.

Henderson IC (1993). Risk factors for breasts cancer development. Cancer 71(Suppl 6):2127-2140.

Henle W and Henle G (1979). Seroepidemiology of the virus. In: Epstein MA and Achong BG, editors. The Epstein-Barr virus. Berlin: Springer-Verlag, 61-78.

Herbst H, Dallenbach F, Hummel M, Niedobitek G, Pileri S, Muller-Lantzsch N, and Stein H (1991). Epstein-Barr virus latent membrane protein expression in Hodgkin and ReedSternberg cells. Proc Natl Acad Sci USA 88:4766-4770.

Horiuchi K, Mishima K, Ohsawa M, and Aozasa K (1994). Carcinoma of stomach and breast with lymphoid stroma: Localisation of Epstein-Barr virus. J Clin Pathol 47:538-540.

Imai S, Koizumi S, Sugiura M, Tokunaga M, Uemura $Y$, Yamamoto N, Tanaka S, Sato E, and Osato T (1994). Gastric carcinoma: Monoclonal epithelial malignant cells expressing Epstein-Barr virus latent infection protein. Proc Natl Acad Sci USA 91:9131-9135.

Jemal A, Thomas A, Murray T, and Thun M (2002). Cancer statistics, 2002. CA Cancer J Clin 52:23-47.

Labrecque LG, Barnes DM, Fentiman IS, and Griffin BE (1995). Epstein-Barr virus in epithelial cell tumors: A breast cancer study. Cancer Res 55:39-45.

Lespagnard L, Cochaux P, Larsimont D, Degeyter M, Velu T, and Heimann R (1995). Absence of Epstein-Barr virus in medullary carcinoma of the breast as demonstrated by immunophenotyping, in situ hybridization and polymerase chain reaction. Am J Clin Pathol 103:449-452.

Longnecker R (1998). Molecular/biology of Epstein-Barr virus. In: DJ M, editor. Human tumor viruses. Washington, D.C.: American Society for Microbiology, 135-174 .

Magrath I and Bhatia K (1999). Breast cancer: A new EpsteinBarr virus-associated disease? J Natl Cancer Inst 91:13491350.

McCall SA, Lichy JH, Bijwaard KE, Aguilera NS, Chu WS, and Taubenberger JK (2001). Epstein-Barr virus detection in ductal carcinoma of the breast. J Natl Cancer Inst 93:148150.

Merchant M, Swart R, Katzman RB, Ikeda M, Ikeda A, Dykstra MI, Pierce SK, and Longnecker R (2001). The effects of the Epstein-Barr virus latent membrane protein $2 A$ on $B$ cell function. Int Rev Immunol 20:805-835.

Niedobitek G, Hansmann ML, Herbst H, Young LS, Dienemann D, Hartmann CA, Finn T, Pitteroff S, Welt A, Anagnostopoulos I, et al (1991). Epstein-Barr virus and carcinomas: Undifferentiated carcinomas but not squamous cell carcinomas of the nasopharynx are regularly associated with the virus. J Pathol 165:17-24.
Nyormoi O (1979). The study of Epstein-Barr virus induction by cocultivation of EBV- transformed cells with a mammary carcinoma cell line MCF-7. Eur J Cancer 15:1223-1231.

Old LJ, Boyse EA, Oettgen HF, Harven ED, Geering G, Williamson B, and Clifford $P$ (1966). Precipitating antibody in human serum to an antigen present in cultured Burkitt's lymphoma cells. Proc Natl Acad Sci USA 56:1699-1704.

Pallesen G, Hamilton-Dutoit SJ, Rowe M, and Young LS (1991). Expression of Epstein-Barr virus latent gene products in tumour cells of Hodgkin's disease. Lancet 337:320-322.

Parkin DM, Pisani P, and Ferlay J (1999). Global cancer statistics. CA Cancer J Clin 49:33-64.

Phillips KA, Glendon G, and Knight JA (1999). Putting the risk of breast cancer in perspective. N Engl J Med 340:141-144.

Purtilo DT, Szymanski I, Bhawan J, Yang JP, Hutt LM, Boto W, DeNicola L, Maier R, and Thorley-Lawson D (1978). Epstein-Barr virus infections in the $\mathrm{X}$-linked recessive lymphoproliferative syndrome. Lancet 1:798-801.

Rickinson AB and Kieff E (1996). Epstein-Barr virus. In: Fields $\mathrm{BN}$, Knipe DM, and Howley PM, editors. Fields virology, vol 2. Philadelphia: Lippincott-Raven, 2397-2446.

Scholle F, Bendt KM, and Raab-Traub N (2000). Epstein-Barr virus LMP2A transforms epithelial cells, inhibits cell differentiation, and activates Akt. J Virol 74:10681-10689.

Scholle F, Longnecker R, and Raab-Traub N (1999). Epithelial cell adhesion to extracellular matrix proteins induces tyrosine phosphorylation of the Epstein-Barr virus latent membrane protein 2: A role for C-terminal Src kinase. J Virol 73:47674775.

Shibata D, Tokunaga M, Uemura Y, Sato E, Tanaka S, and Weiss LM (1991). Association of Epstein-Barr virus with undifferentiated gastric carcinomas with intense lymphoid infiltration. Lymphoepithelioma-like carcinoma. Am J Pathol 139:469-474.

Thorley-Lawson DA (2001). Epstein-Barr virus: Exploiting the immune system. Nature Reviews Immunology 1:75-82.

Touitou R, Bonnet-Duquenoy M, and Joab I (2001). Association of Epstein-Barr virus with human mammary carcinoma. Pros and cons. Dis Markers 17:163-165.

Yasui Y, Potter JD, Stanford JL, Rossing MA, Winget MD, Bronner M, and Daling J (2001). Breast cancer risk and "delayed" primary Epstein-Barr virus infection. Cancer Epidemiol Biomarkers Prev 10:9-16.

Yates JL, Warren N, and Sugden B (1985). Stable replication of plasmids derived from Epstein-Barr virus in various mammalian cells. Nature 313:812-815.

zur Hausen $H$, Schulte-Holthausen $H$, Klein G, Henle W, Henle G, Clifford P, and Santesson L (1970). EBV DNA in biopsies of Burkitt tumours and anaplastic carcinomas of the nasopharynx. Nature 228:1056-1058. 